\title{
Analysis and Simulation of PV based Inverter System
}

\author{
G.Mamatha $^{\# 1}$,K. V. Siva Reddy ${ }^{*^{2}}$, P. Srinivasa Varma ${ }^{\# 3}$ \\ EEE Department, K L University, Vaddeswaram. \\ ${ }^{1}$ mamatha.eee242@gmail.com \\ 2sivareddy.v.k@gmail.com, \\ 3pinnivarma@gmail.com
}

\begin{abstract}
As the demand for energy is continuously increasing day by day, increased concentration on reduction of emissions from conventional energy sources and depletion of fossil fuels made to think other alternative sources of energy. Among various other energy sources, energy generated by photovoltaic (PV) array of cells playing a major role now a days. By the physical and chemical phenomenon Solar cell or pv cell converts energy of light into electricity without any intermediate conversion of energy. A photovoltaic (PV) inverter system which consists of PV module, and inverter. The main purpose of inverter is to convert dc to ac. But ,by the conversion process power quality in not upto the mark due to harmonics. Thus to improve the power quality and reduce the harmonics while converting power using inverter with different levels are compared and analyzed.. A converter is also developed to inter-connect the PV module and inverter without disturbances. Thus, Simulation of solar cell and pv cell with inverter and converter is carried out in MATLAB/Sim.
\end{abstract}

Keywords-Photo voltaic panel (PV), PV Module, Harmonics

\section{INTRODUCTION}

Sun fueled essentialness is splendid light and warmth from the Sun handled using an extent of continually propelling headways, for instance, sun arranged warming, photograph voltaic, sun based warm imperativeness, sun controlled building and mimicked photosynthesis. It is basic wellspring of renewable essentialness and its advancements are widely portrayed as either uninvolved sun arranged or dynamic sun based depending upon the way they get and circle sun situated imperativeness or convert it into sun controlled power. Dynamic daylight based methodology join the usage of photovoltaic systems, concentrated sun situated constrain and sun controlled water warming to equip the imperativeness. Withdrawn daylight based systems consolidate orchestrating an attempting to the Sun, selecting materials with extraordinary warm mass or light dispersing properties, and sketching out spaces that regularly course air [2].

As one of the noticeable renewable vitality assets, photovoltaic (PV) era has been progressively increasing impressive consideration among industry players all around the globe. In the greater part of the PV application ns, the key capacity of PV framework is to concentrate most extreme force from PV module amid the daytime.The power-voltage characteristics have nonlinear qualities that rely on upon ecological conditions like irradiance and temperature. With change in irradiance and temperature there will be change in yield voltage too. This yield voltage will be gotten in DC structure which is ir-directed, so a DC-DC converter is utilized to change over the ir-managed DC into controlled DC. Since a large portion of our applications require air conditioning power we utilize inverter to change over DC into air conditioning.Amid this change from DC to AC, music influence the Power quality a considerable measure. Therefore, in this project different levels of inverters are used reduce the harmonic effect, to use the power efficiently [14].

\section{PHOTO VOLTAIC MODULE:}

It is an electrical device made of semiconductor materials has an equivalent circuit as shown in the Fig1 tells a current source in parallel with diode and internal resistances.

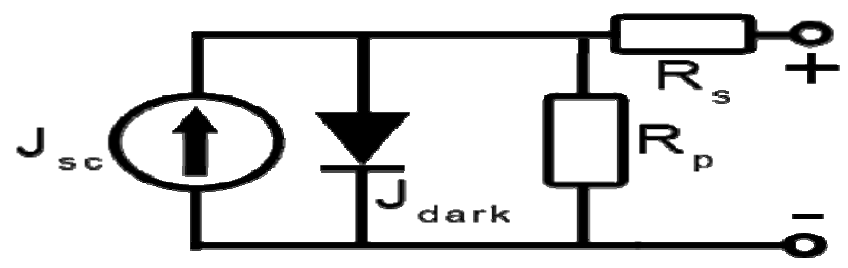

Fig.1. Proportional circuit of PV cell

The cell photocurrent is denoted by the current source $\mathrm{I}_{p h}$. The intrinsic shunt and series resistances of the cell are denoted by $\mathrm{R}_{p}$ and $\mathrm{R}_{s}$ respectively. As the value of $\mathrm{R}_{s}$ is very small than that of $\mathrm{R}_{p}$, it may be neglected for simplification [5]. 
Conditions which characterize the Mathematical Equations of a PV Cell are given underneath

$$
\begin{aligned}
& V t=k \frac{T o p}{q} \\
& V o c=V t \ln \left(\frac{I p h}{I s}\right) \\
& I d=\left[\exp \frac{(V+I R s)}{(n V t C N s)}\right] I s N p \\
& I s=I r s\left(\frac{\text { Top }}{\text { Tref }}\right)^{3} \exp \left[\frac{q E g}{n k}\left(\frac{1}{T o p}-\frac{1}{\text { Tref }}\right]\right. \\
& I r s=\frac{I s c}{\left[\exp \left(\frac{\text { Vov } q}{\text { KCTop }}\right)-1\right]} \\
& I s h=\frac{V+I R s}{R p} \\
& I p h=G k[I s c+K i(T o p-T r e f)] \\
& I=I p h N p-I d-I s h
\end{aligned}
$$

\begin{tabular}{|c|c|}
\hline MAXIMUM POWER & $60 \mathrm{~W}$ \\
\hline PEAK VOLTAGE AT MAXIMUM POWER $\left(\mathrm{V}_{M P}\right)$ & $17.1 \mathrm{~V}$ \\
\hline PEAK CURRENT AT MAXIMUM POWER (I $\left.{ }_{M P}\right)$ & 3.5A \\
\hline OPEN CIRCUIT VOLTAGE AT $\left(\mathrm{V}_{O C}\right)$ & $21.1 \mathrm{~V}$ \\
\hline SHORT CIRCUIT CURRENT (I $S C)$ & 3.8A \\
\hline SERIES CONNECTED CELLS (N S ) & 36 \\
\hline PARALLEL CONNECTED CELLS (N P ) & 1 \\
\hline
\end{tabular}

The PV module is designed in MATLAB using above mathematical equations. To get the the PV current the electrical parameters of the module $\left(\mathrm{I}_{s c}, \mathrm{~V}_{o c}, n\right)$ and the variable Voltage, Temperature $(T)$ and Irradiation $(G)$ are used as the inputs to the model .

The reference module for simulation of Solar panel with $60 \mathrm{~W}$ peak power is taken and the respective details are given in Table1 [3].

TABLE I. solar $60 \mathrm{~W}$ pv module specifications

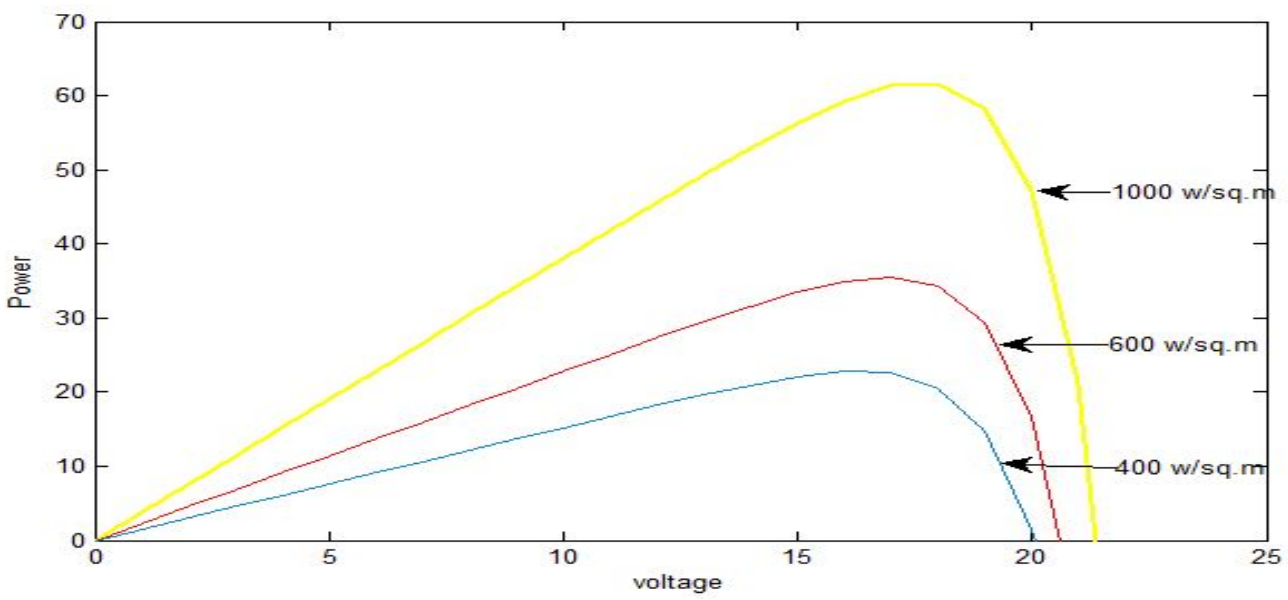

Fig. 2. P-V attributes for various light levels at steady temperature of $25^{\circ} \mathrm{C}$ 


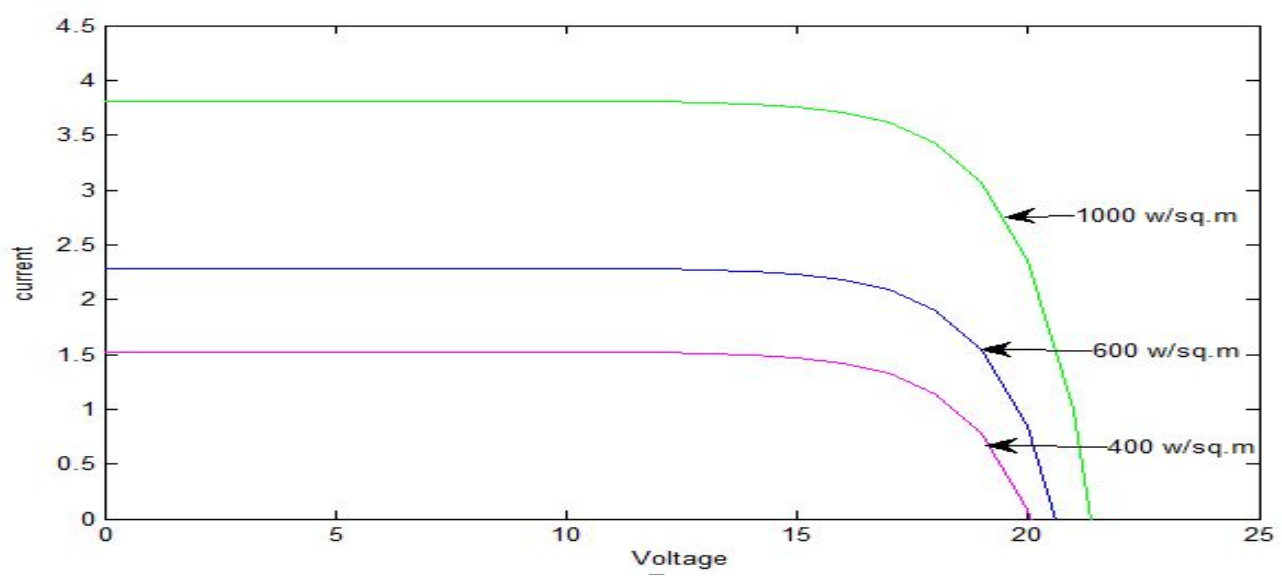

Fig. 3. I-V attributes for various light levels at steady temperature of $25^{\circ} \mathrm{C}$

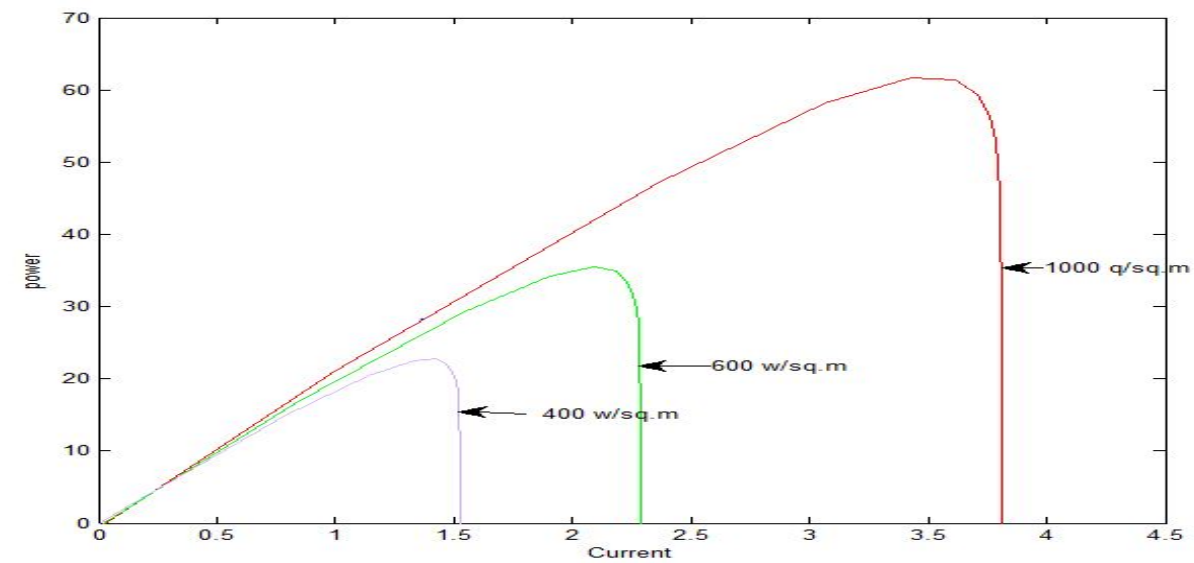

Fig. 4. P-I attributes for various light levels at consistent temperature of $25^{\circ} \mathrm{C}$

Higher the sun based illumination, the contribution to the sun oriented cell will be high and subsequently control extent would increment for the same voltage esteem. open circuit voltage increments with expansion in the sun powered light. This is because of the way that, when more daylight episodes on to the sun based cell, the electrons are supplied with higher excitation vitality, accordingly expanding the electron versatility and subsequently more power is created.

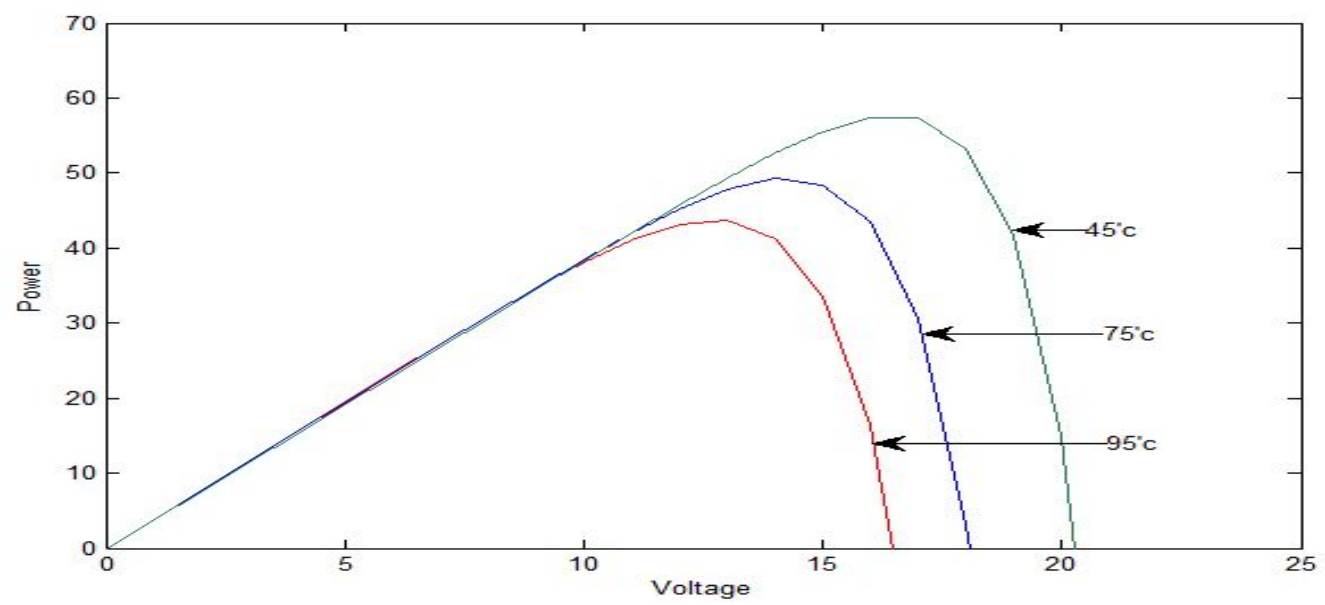

Fig. 5. P-V attributes for various temperatures at consistent illumination of $1000 \mathrm{w} / \mathrm{sqm}$ 


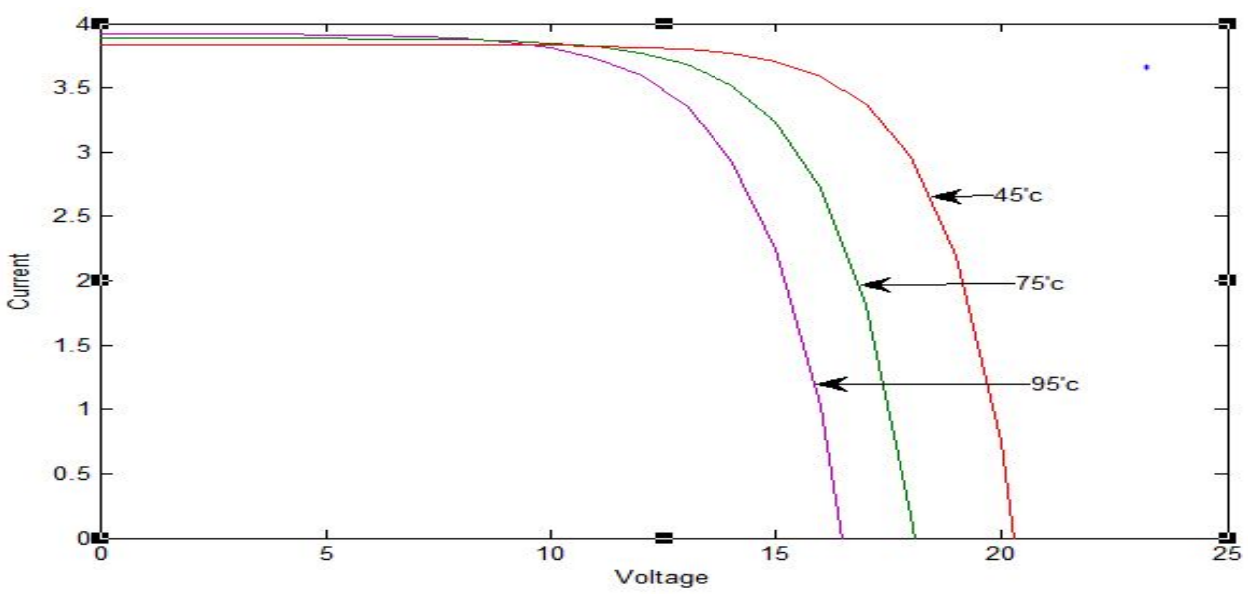

Fig. 6. I-V attributes for various temperatures at consistent illumination of $1000 \mathrm{w} / \mathrm{sqm}$

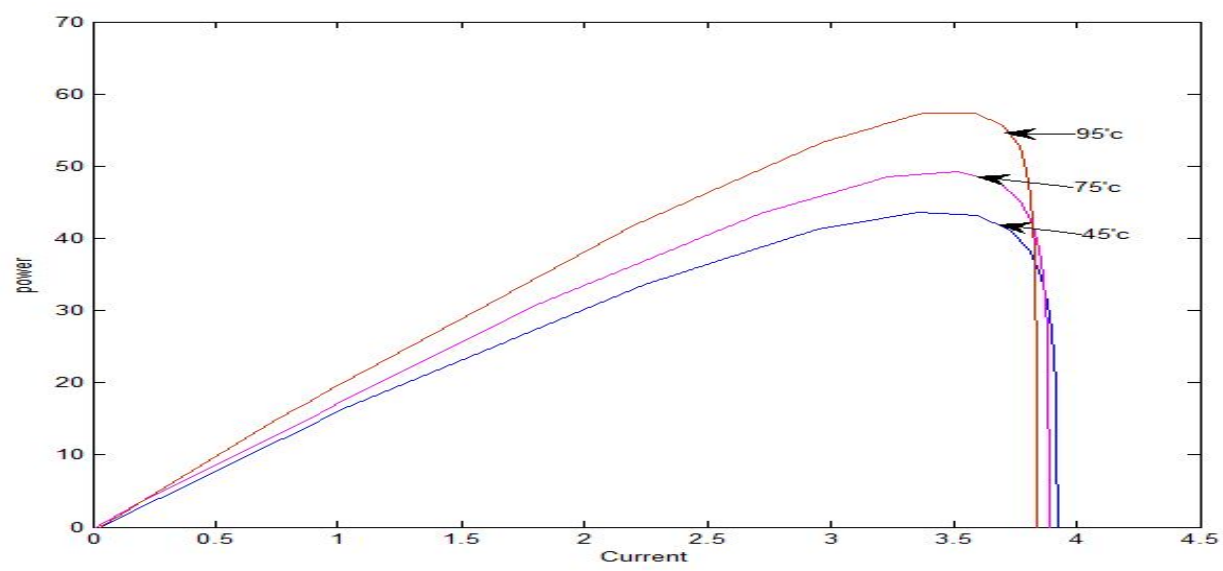

Fig. 7. P-I attributes for various temperatures at consistent illumination of $1000 \mathrm{w} / \mathrm{sqm}$

Despite what might be expected the temperature increment around the sun powered cell negatively affects the force era capacity. Increment in temperature is joined by a reduction in the open circuit voltage esteem. Increment in the temperature causes increment in the band hole of the material in this way more vitality is required to cross the obstruction. In this manner proficiency of sun oriented cell is diminished [4].

\section{DC-DC CONVERTER}

DC-DC converter is a device which converts DC voltage from one level to another level. It can be from low voltage to high voltage or high voltage to low voltages. Exactly when a quick affiliation is finished between the source and the load, the use of the PV module is ir-overseen. It is critical to vanquish this issue by including a modification circuit between the source and the pile [6]. The support circuit consists of a vitality putting away component Diode, a capacitor, a Inductor, a heap and an exchanging Device like Mosfet, BJT and so on. Circuit chart of support converter is appeared in figure 2 underneath [6].

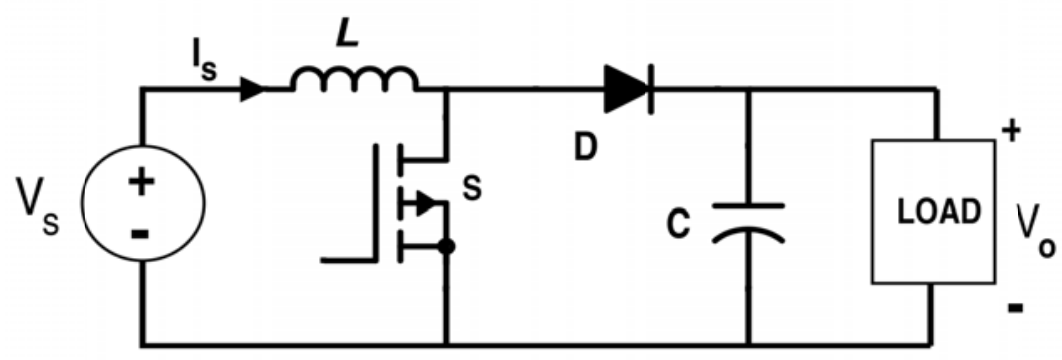

Fig. 8. Boost Converter 


\section{INPUT AND OUTPUT OF CONVERTER}

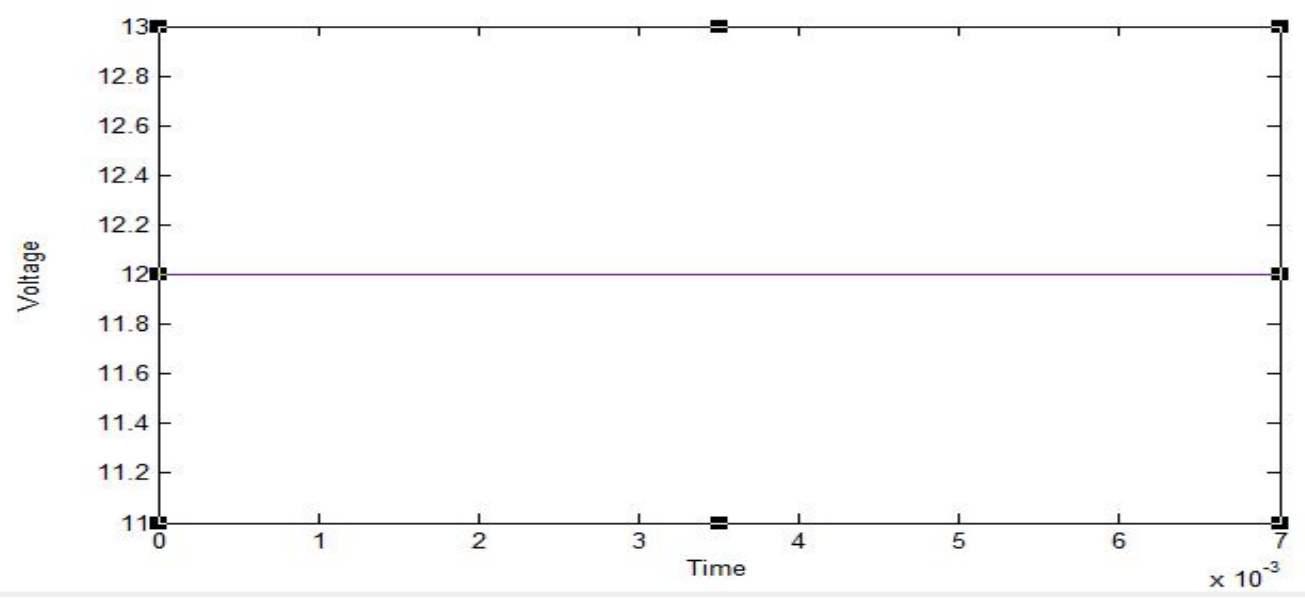

Fig. 9. Input waveform of converter

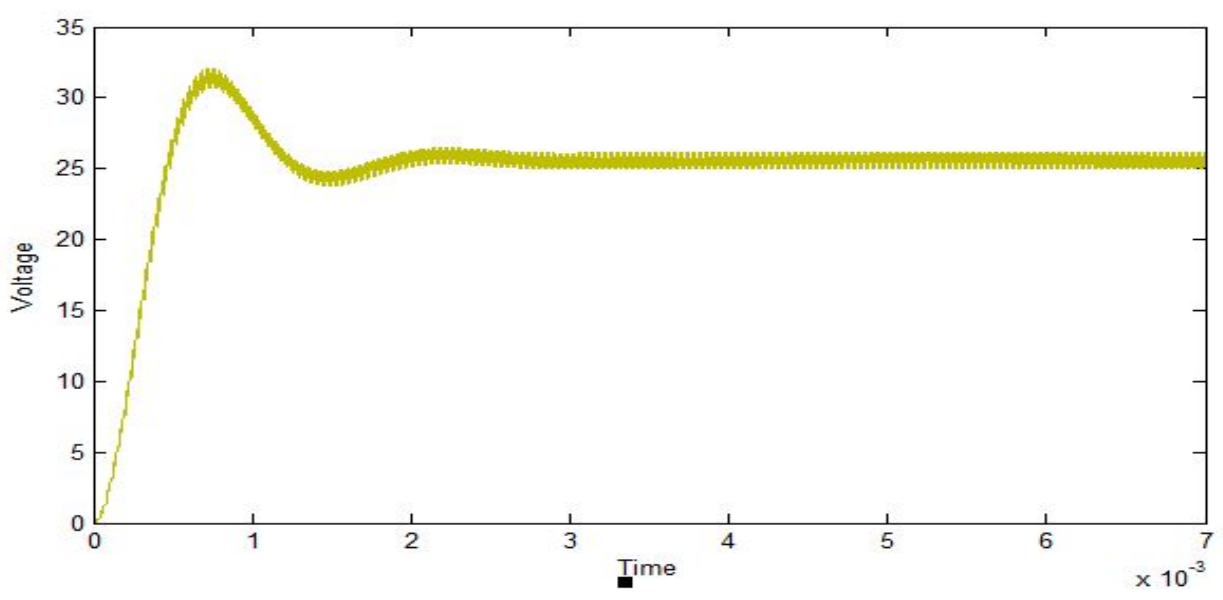

Fig. 10. output waveform of converter

For example the input voltage $12 \mathrm{~V}$, is taken and the converter used is boost converter so the output voltage obtained will be nearly equal to double than the applied..Now to convert the ir-regulated DC output voltage of PV module to regulated DC, PV module output voltage is given as input to boost converter, then the output is connected to converter

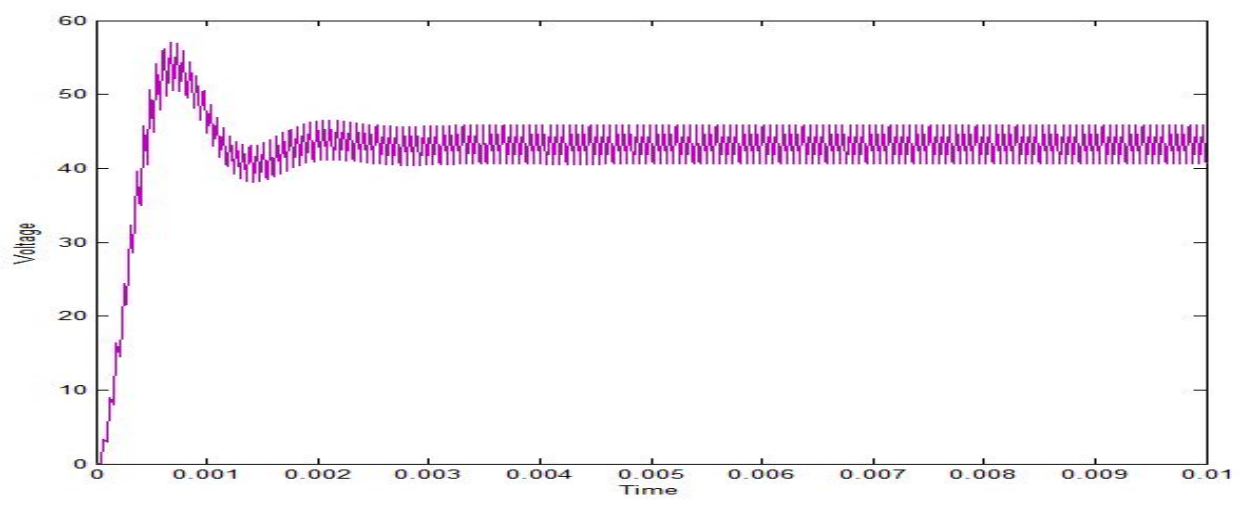

Fig. 11. output waveform when PV module

Here the inputs to the module are isolation and temperature. With changes in input parameters output voltage also changes. By change in that output voltage of PV module converter output voltage also changes. 


\section{INVERTER}

Dc-to Ac converters are known as inverters Inverter output voltage could be variable or fixed at variable or fixed frequency. By pulse width modulation control with in inverter will give different voltage levels. Ratio of output voltage to dc input voltage is known as gain. A Power inverter can be absolutely electronic or might be a blend of mechanical impacts, (for occurrence, a pivoting device) and electronic gear. There are a few sorts of inverters. In this anticipate fell H-span multi-level inverter is utilized to change over the DC to AC. The circuit is demonstrated as follows

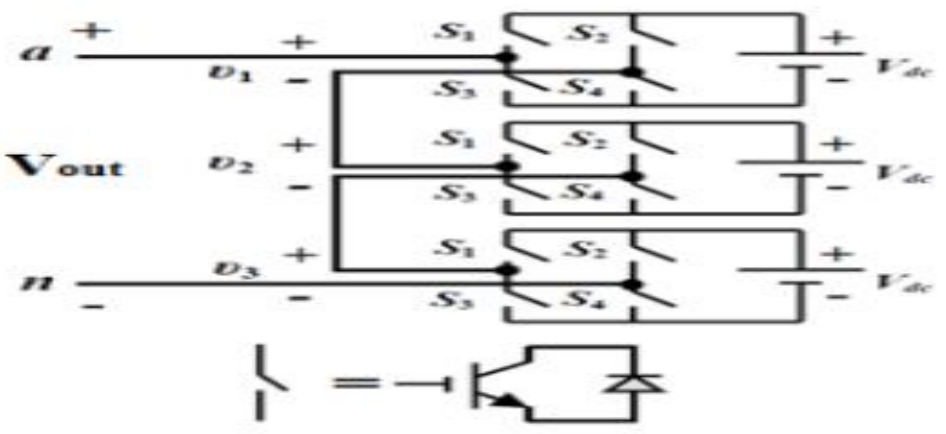

Fig.12. H-bridge7-level inverter

Consider a seven level inverter; it requires 12 IGBT switches and three dc sources. The force circuit of inverter is appeared in the figure. A fell H-traverse multilevel inverter is just an arrangement relationship of various H-navigate inverters. Every H-traverse inverter has the same setup as an average spot single-stage fullassociate inverter [7].

The fell H-traverse multilevel inverter considers Separate DC Sources (SDCSs) to go on an air circulation and cooling framework voltage waveform. Each H-explore inverter is connected with its own specific DC source Vdc. By falling the air circulation and cooling framework yields of each $\mathrm{H}$-cross inverter, a ventilation framework voltage waveform is passed on. By closing the fitting switches, each $\mathrm{H}$-cross inverter can make three particular voltages: +Vdc, 0 and - Vdc [9].In this anticipate diverse levels of inverter are composed and yield is concentrated on to off the switches pulse width modulation (PWM) technique is used.

\section{PWM TECHNIQUE}

PWM is used all around as a framework for driving cooling contraptions with a DC power source. In principal equipment, a PWM sign is passed on by connecting with the reference and transporter signal from a comparator and which makes the posted notification in setting of the ability among two inputs. The basic reference is in sinusoidal waveform and the vehicle wave is a triangle or "saw tooth" wave which works at a repeat basically more unmistakable than the reference wave [11].

Right when the Transport sign surpasses the yield is at one position, and when the position surpasses the transporter the yield is in backward state. The structure is showed up underneath in Fig. A, of transporter in blue, the reference in color red, and the yield in color green [10].
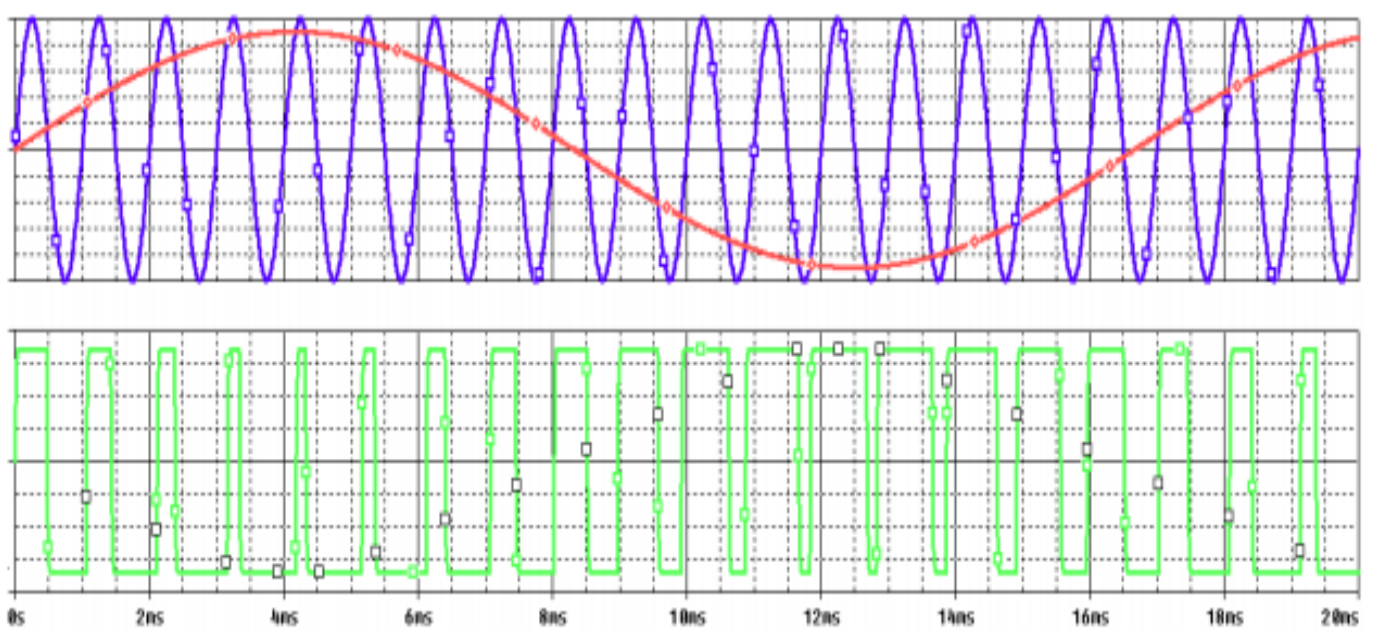

Fig.13. wave form of pulse width modulation technique 


\section{INPUT AND OUTPUT WAVEFORMS OF DIFFERENT LEVELS OF INVERTERS}

For cascaded H-bridge 7- level inverter we use 3 input DC sources, therefore for example if we give $100 \mathrm{v}$ as input then the output voltage waveform is given below.

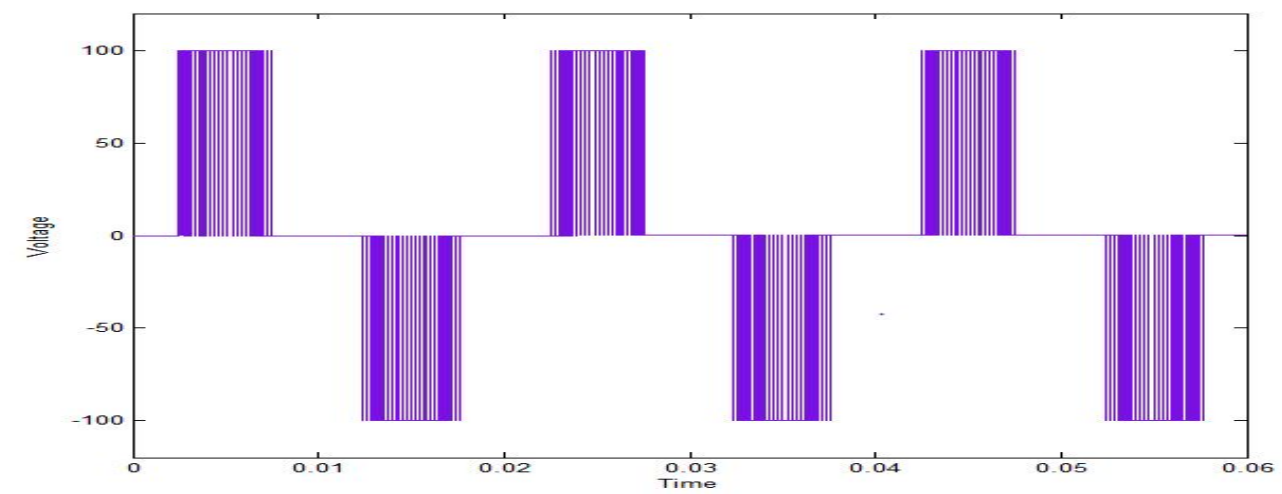

Fig.14. 3-level inverter output waveform.

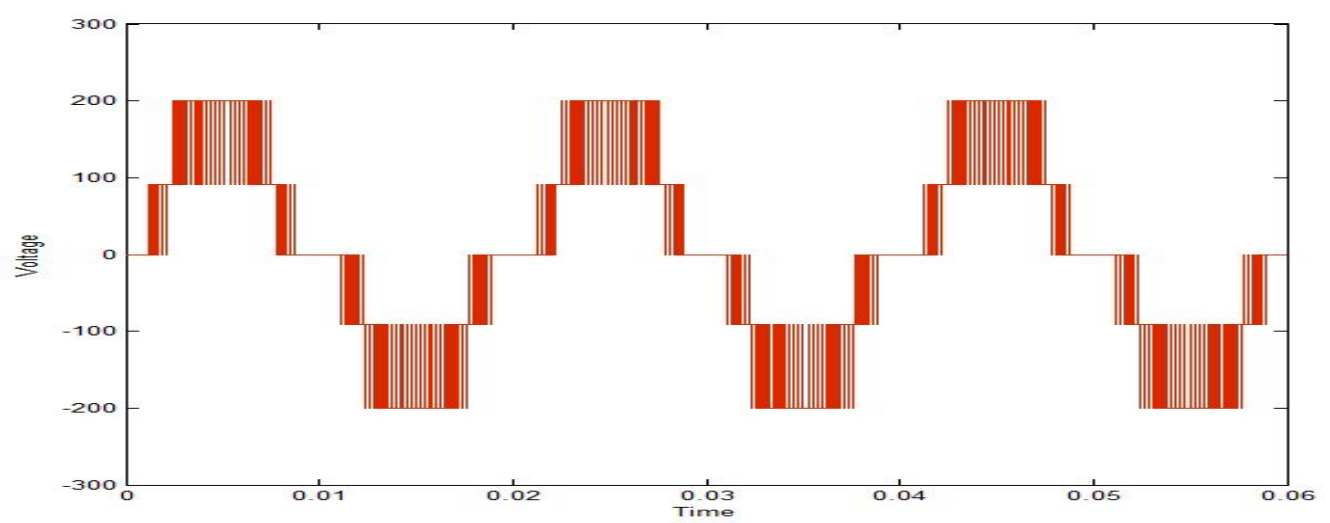

Fig.15. 5-level inverter output waveform

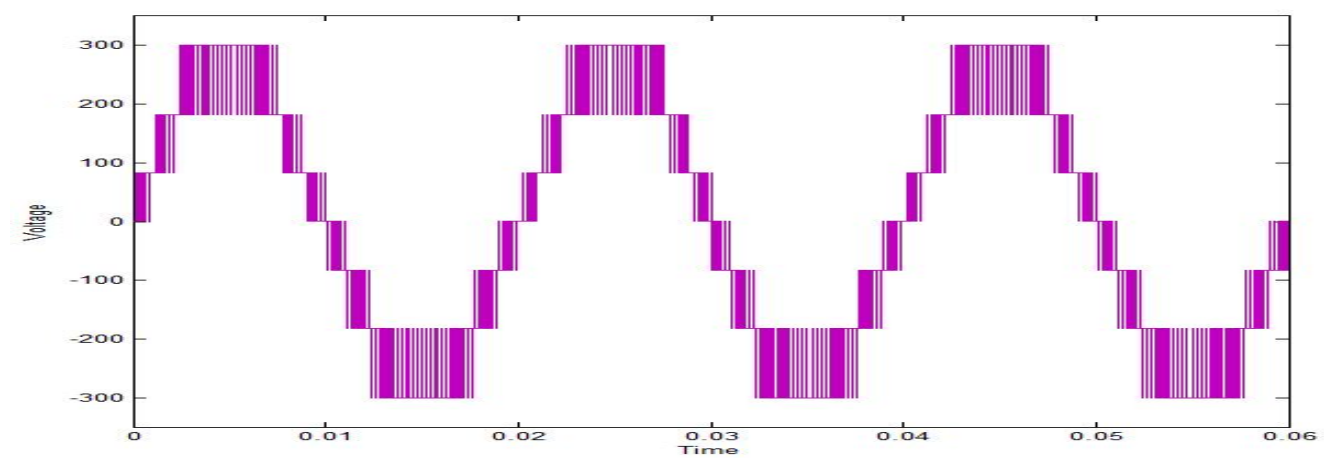

Fig.16. output waveform of 7-level inverter

Here above output waveforms of 3-Level, 5-Level and 7-Level inverter are shown with out pv panel and converter.

After connecting designed pv panel and converter with different levels of Inverters the output waveforms are shown below. 
Connection with 3-Level inverter

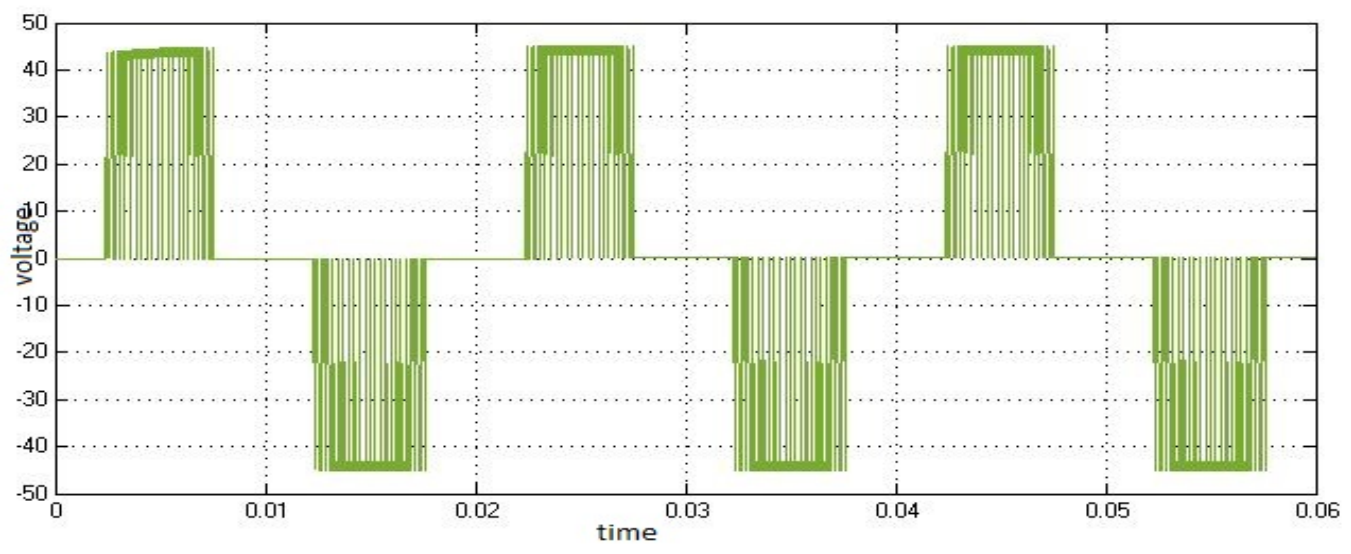

Fig.17. 3-level inverter output waveform connected to PV panel

Connection of 5-Level inverter with PV module

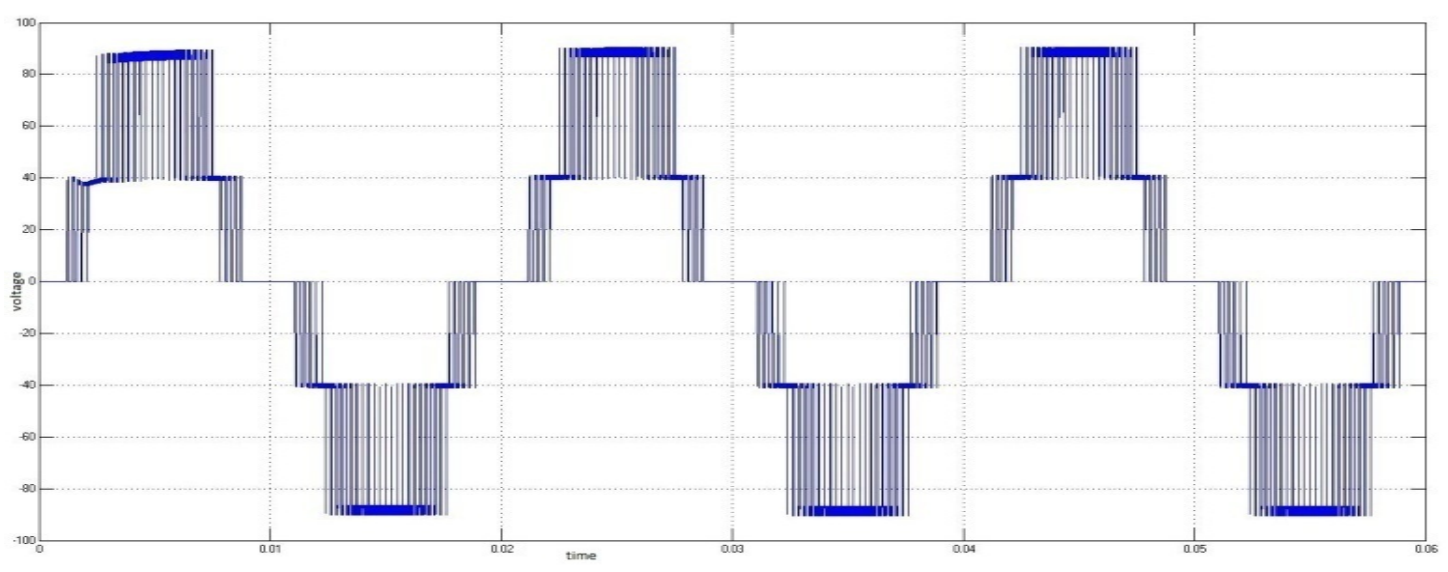

Fig.18. 5-level inverter output waveform connected to PV panel.

Connection with 7-Level inverter

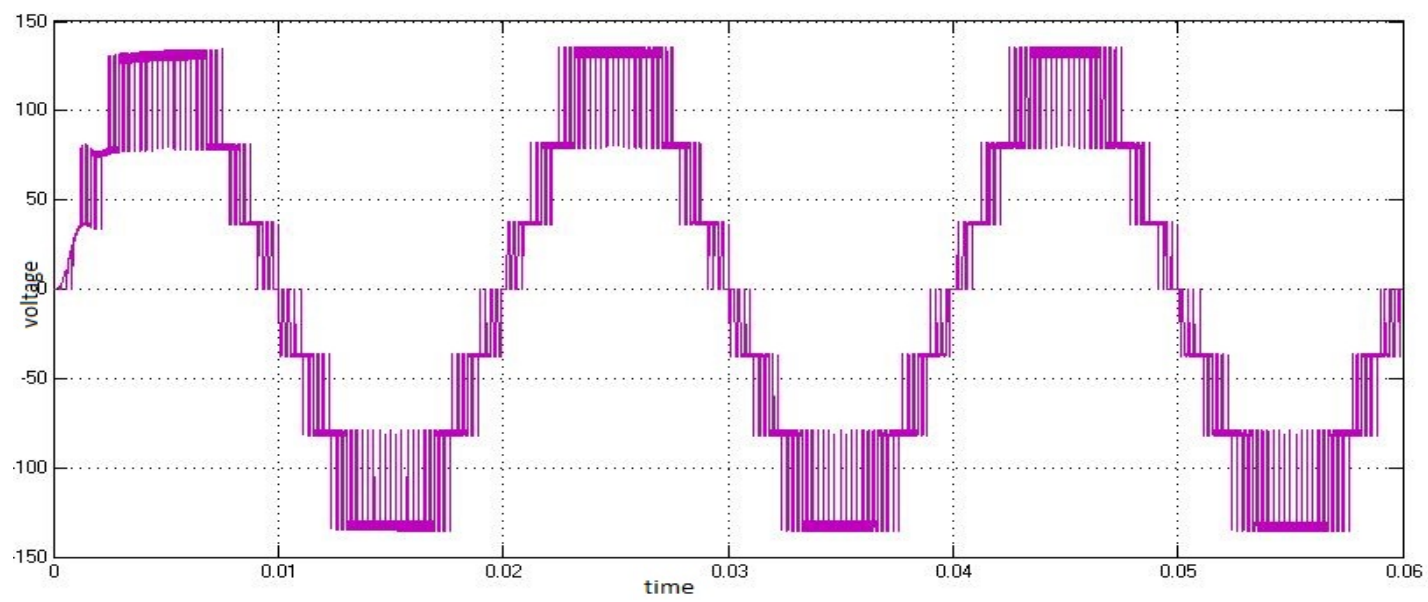

Fig.19. 7-level inverter output waveform connected to PV panel.

From, these waveforms we Observe that With increase in levels of inverter output voltage increases with reduction in harmonics. It is very effective in grid connected systems.

\section{CONCLUSION}

Thus, finally the analysis is carried on wave forms of different levels of inverters, from that it is observed that with increase in the levels of inverter the harmonic content gets reduced so these inverters are used for interconnection of PV Module to Grid system for reducing Harmonics. Also characteristics of PV module with different irradiations and different temperatures are also studied. 


\section{REFERENCES}

[1] G.Mamatha, Assessment Of Different Mppt Techniques For Pv System, Journal of electrical engineering,vol 16/2016

[2] G.Mamatha,Perturb and Observe MPPT Algorithm Implementation for PV Applications, International Journal of Computer Science and Information Technologies, Vol. 6 (2), 2015, 1884-1887

[3] G.Mamatha, A New maximum power point tracking method for PV system, Int.J.Computer Technology \& Applications,Vol 6 (2),255 264

[4] G.Mostafa, F.Khan,An efficient menthod of solar panel energy measurement system,IEEE, 2009.

[5] L.Gao, R.A.Dougal, S.Liu, P.lotova, parallel connected solar pv system to address fluctuating shadow conditions.

[6] T. Esram and P. L. Chapman, “Comparison of photovoltaic array maximum power point tracking techniques,” IEEE Transactions onEnergy Conversion, vol. 22, no. 2, pp. 439-449, 2007

[7] “Trends in photovoltaic applications. Survey report of selected IEA countries between 1992 and 2009”, International Energy Agency, Report IEAPVPS Task 1 T1-19:2010, 2010

[8] D.Burnelli, C.Moser, L.Thiele, L.Benini, Design of a Solar-Harvesting Circuit for BatterylessEmbedded Systems,IEEE Transactions on Circuits and Systems I: Regular Papers (Volume:56, Issue: 11 )

[9] B.M. Hasaneen, A.A.Elbaset Mohammed Design and simulation of DC/DC boost converter,Power System Conference, 2008. MEPCON 2008. 12th International Middle-East,2008

[10] S.Marsi, P.W.Chan, Design and develop- pment of a DC-DC boost converter with constant output voltage,Intelligent and Advanced Systems (ICIAS), 2010 International Conference.

[11] M.Marodkar, S.Adhau, M.Sabley, P.Adhau,Design and simulation of DC-DC converters for Photovoltaic system based on MATLAB, IEEE, Industrial Instrumentation and Control (ICIC), 2015 International Conference

[12] S.S.Shema, I.Daut, M.Irwanto, C.Shatri, Study of inverter design and topologies for photovoltaic system, IEEE,Electrical, Control and Computer Engineering (INECCE), 2011 International Conference.

[13] H. f. Zhou , Z. l. Xu ; Z. h. Lin ; R. j. Wang ; J. d. Dong ; Y. q. Huang, Simulation Design of Inverter in Solar Photovoltaic System Based on MCU, IEEE, 2009 Symposium on Photonics and Optoelectronics.

[14] P. Srinivasa Varma and M. Yateesh Kumar, “A Comparative Study for Alleviation of Current Harmonics using PI/FUZZY Controller based PV-APF System”, Indian Journal of Science and Technology, Vol. 9, No.23, June 2016. 